\title{
SBF-1 exerts strong anticervical cancer effect through inducing endoplasmic reticulum stress-associated cell death via targeting sarco/endoplasmic reticulum $\mathrm{Ca}^{2+}$-ATPase 2
}

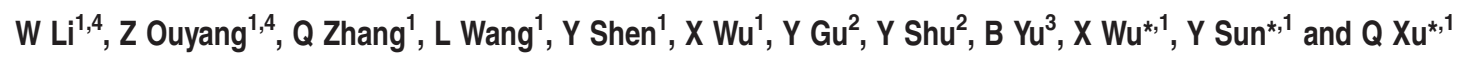

Cervical cancer is one of the most common carcinomas in the genital system. In the present study, we report that SBF-1, a synthetic steroidal glycoside, has a strong antigrowth activity against human cervical cancer cells in vitro and in vivo. SBF-1 suppressed the growth, migration and colony formation of HeLa cells. In addition, severe endoplasmic reticulum (ER) stress was triggered by SBF-1, and 4-phenyl-butyric acid, a chemical chaperone, partially reversed SBF-1-induced cell death. To uncover the target protein of SBF-1, the compound was labeled with biotin. The biotin-labeled SBF-1 bound to sarco/ER Ca ${ }^{2+}$-ATPase 2 (SERCA2) and colocalized with SERCA2 in HeLa cells. Moreover, SBF-1 inhibited SERCA activity, depleted ER $\mathrm{Ca}^{2+}$ and increased cytosolic $\mathrm{Ca}^{2+}$ levels. 1,2-Bis(o-aminophenoxy)ethane- $N, N, N^{\prime}, N^{\prime}$-tetraacetic acid, a chelator of $\mathrm{Ca}^{2+}$, partially blocked SBF-1-induced ER stress and growth inhibition. Importantly, knockdown of SERCA2 increased the sensitivity of HeLa cells to SBF-1-induced ER stress and cell death, whereas overexpression of SERCA2 decreased this sensitivity. Furthermore, SBF-1 induced growth suppression and apoptosis in HeLa xenografts, which is closely related to the induction of ER stress and inhibition of SERCA activity. Finally, SERCA2 expression was elevated in human cervical cancer tissues $(n=299)$ and lymph node metastasis $(n=8)$, as compared with normal cervix tissues $(n=23)$, with a positive correlation with clinical stages. In all, these results suggest that SBF-1 disrupts $\mathrm{Ca}^{2+}$ homeostasis and causes ER stress-associated cell death through directly binding to SERCA2 and inhibiting SERCA activity. Our findings also indicate that SERCA2 is a potential therapeutic target for human cervical cancer.

Cell Death and Disease (2014) 5, e1581; doi:10.1038/cddis.2014.538; published online 18 December 2014

The endoplasmic reticulum $(E R)$ is a membranous system that is essential for the function and survival of mammalian cells. ${ }^{1}$ To achieve an optimum state for survival, a cell may undergo various pathways in the $E R$, such as ones that regulate protein folding, posttranslational modifications, lipid and steroid synthesis, gene expression, cellular metabolism and calcium signaling. When the pathways are disturbed, ER functions become overwhelmed and the accumulation of misfolded proteins within the ER lumen ultimately leads to ER stress and initiates the unfolded protein response (UPR) to restore ER proteostasis. $^{2,3}$ The UPR is generally considered to be the transcriptional induction of molecular chaperones in response to ER stress. ${ }^{4}$ Three ER stress arms have been identified so far: protein kinase RNA-like ER kinase (PERK), inositolrequiring enzyme-1 (IRE1) and activating transcription factor-6 (ATF6). . $^{3,5,6}$ These three ER stress arms can act as coregulators of most targets to ensure the redundancy and robustness of this adaptive response. ${ }^{3,7}$ If the response fails or prolongs, apoptotic cell death ensues. ${ }^{3,8}$

Calcium homeostasis is involved in a multitude of signaling in $E R$, in which calcium is actively accumulated by sarco/ER $\mathrm{Ca}^{2+}$-ATPase (SERCA) transport ATPases. ${ }^{9,10}$ As SERCAdependent calcium transport is the only calcium uptake mechanism in this organelle, the regulation of SERCA function by the cell constitutes a key mechanism to adjust calcium homeostasis in the ER depending on the cell type and its state of differentiation. ${ }^{10}$ The SERCA pump is encoded by a family of three genes, SERCA1, 2 and 3, which are highly conserved but localized on different chromosomes. ${ }^{11}$ At present, more than 10 different SERCA isoforms have been discovered in this family. These isoforms exhibit both tissue and developmental specificity, suggesting that they contribute to unique physiological properties of the tissue in which they are expressed. ${ }^{11,12}$ SERCA expression levels can undergo

\footnotetext{
${ }^{1}$ State Key Laboratory of Pharmaceutical Biotechnology, School of Life Sciences, Nanjing University, 22 Hankou Road, Nanjing 210093, China; ${ }^{2}$ Department of Oncology, The First Affiliated Hospital of Nanjing Medical University, Nanjing 210029, China and ${ }^{3}$ State Key Laboratory of Bio-organic and Natural Products Chemistry, Shanghai Institute of Organic Chemistry, Chinese Academy of Sciences, Shanghai 200032, China

${ }^{*}$ Corresponding author: Q Xu or Y Sun or X Wu, State Key Laboratory of Pharmaceutical Biotechnology, School of Life Sciences, Nanjing University, 22 Hankou Road, Nanjing 210093 , Jiangsu, China. Tel/Fax: +86 25 83597620; E-mail: wuxf@ nju.edu.cn (QX) or yangsun@ @ju.edu.cn (YS) or molpharm @ 163.com (XW) ${ }^{4}$ These authors contributed equally to this work.

Abbreviations: SERCA2, sarco/endoplasmic reticulum Ca2+-ATPase 2; ER, endoplasmic reticulum; BAPTA, 1,2-bis(0-aminophenoxy)ethane- $N, N, N^{\prime}, N^{\prime}$-tetraacetic acid; PBA, 4-phenyl-butyric acid; CHOP, C/EBP homologous protein; elF, eukaryotic translation initiation factor; GRP, glucose-regulated protein; ATF, activating transcription factor; XBP, X-box binding protein; MTT, 3-(4,5-Dimethylthiazol-2-yl)-2,5-diphenyltetrazolium bromide; DMSO, dimethyl sulfoxide

Received 23.7.14; revised 02.10.14; accepted 03.11.14; Edited by R Johnstone
} 
significant changes during cell differentiation or tumorigenesis, leading to modified ER calcium storage. ${ }^{10}$ For example, expression levels of SERCA3, a lower calcium affinity calcium pump, are highly variable. In several cell systems, SERCA3 expression is selectively induced during differentiation, whereas during tumorigenesis SERCA3 expression is decreased. ${ }^{10,13-18}$ Diverse levels of SERCA2 are also correlated with tumorigenesis. ${ }^{19-21}$

Cervical cancer is the third most common carcinoma in women worldwide. ${ }^{22-24}$ The American Cancer Society estimates that 12360 new cases and 4020 deaths of cervical cancer are projected to occur in the United States in $2014 .^{22}$ Despite more and more efforts are being made to improve therapy, a significant proportion of women still die from recurrence and chemoresistance, ${ }^{24}$ which is a hallmark of cancer cells. ${ }^{25,26}$ Searching for an efficient agent is still a requirement for the therapy of the cancer. Among such efforts, induction of ER stress by targeting SERCA might be a potential therapeutic strategy to treat apoptosis-resistant cancer cells. ${ }^{27,28}$ Our previous study identified that SBF-1, a synthetic steroidal glycoside, had a very strong antitumor activity in various cancer types. ${ }^{29,30}$ Herein, we report a new property of SBF-1 for characterizing its anticancer activity as a SERCA inhibitor that directly binds to SERCA2. In human cervical cancer cells, ER $\mathrm{Ca}^{2+}$ homeostasis is disrupted and ER stress-mediated cell death is induced by SBF-1 both in vitro and in vivo.

\section{Results}

SBF-1 induces ER stress-associated cell death in human cervical cancer HeLa cells. As shown in Figure 1, SBF-1 concentration- (Figure 1a) and time-dependently (Figure 1b) inhibited growth of a human cervical cancer cell line (HeLa). Colony formation (Figure 1c) and migration ability (Figure 1d) of HeLa cells were also significantly repressed by SBF-1 treatment. Then, we observed that protein levels of ATF6 ( $\mathrm{N}$ terminal, p50), spliced form of X-box-binding protein 1 (XBP1s), phospho-eukaryotic translation initiation factor $2 \mathrm{~A}$ $\left(\right.$ elF2 $a^{\text {Ser51 }}$ ) and C/EBP homologous protein $(\mathrm{CHOP})$ were significantly increased after exposure to $100 \mathrm{nM}$ SBF-1 (Figure 1e). The mRNA levels of CALNEXIN, CALRETICULIN, CHOP, glucose-regulated protein 78 (GRP78), GRP94 and GRP170 were also significantly increased by $100 \mathrm{nM}$ SBF-1 (Figure 1f). Moreover, $100 \mathrm{nM}$ SBF-1 time-dependently increased the protein levels of ATF6 (p50), XBP1s and phospho-elF2 $a^{\text {Ser51 }}$ (Figure $1 \mathrm{~g}$ ), and increased the mRNA levels of CALNEXIN, CALRETICULIN, CHOP, GRP78, GRP94 and GPR170 (Figure 1h). 4-Phenyl-butyric acid (PBA), a chemical chaperone reported to be an inhibitor of ER stress, ${ }^{27,31}$ partially reversed SBF-1-induced growth inhibition, where PBA increased the 50\% inhibitory concentration $\left(\mathrm{IC}_{50}\right)$ of SBF-1 from $54.49 \pm 6.32$ to $236.25 \pm 25.31 \mathrm{nM}$ (Figure 1i). These results suggest that SBF-1-induced growth inhibition of HeLa cells is associated with ER stress.

SBF-1 binds to SERCA2 and increases the intracellular $\mathrm{Ca}^{2+}$ levels. To find out binding proteins of SBF-1, SBF-1 was labeled with biotin (Supplementary Figure S2a). The biotin conjugate of SBF-1 (biotin-SBF-1) still showed a strong antigrowth activity $\left(\mathrm{IC}_{50}, 436.63 \pm 48.79 \mathrm{nM}\right)$ despite an obvious decrease as compared with SBF-1 (IC $\mathrm{IC}_{50}$, $45.66 \pm 6.27 \mathrm{nM}$; Supplementary Figure S2b). Biotin-SBF-1 was then incubated with HeLa whole-cell lysates and streptavidin-conjugated sepharose beads in the presence or absence of 10 - to 20 -fold excess of SBF-1. The proteins bound to the beads were separated with SDS-PAGE and the bands between 100 and $130 \mathrm{kDa}$ were cut and analyzed with liquid chromatography-mass spectrometry (LC/MS). Sarco/ ER $\mathrm{Ca}^{2+}$-ATPase 2 (SERCA2), the most abundant SERCA isoform in HeLa cells (Supplementary Figure S3a), was identified to be a binding protein of SBF-1 (Figures $2 a$ and $b$ ), and biotin-SBF-1 colocalized with SERCA2 in HeLa cells (Figure 2c). Furthermore, SERCA activity of HeLa cells was significantly suppressed by both 10 and $100 \mathrm{nM}$ SBF-1 (Figure 2d) and the protein level of SERCA2 was compensatorily increased (Supplementary Figures S3b and c), whereas the mRNA level of SERCA2 was not changed (Supplementary Figure S3d). Moreover, ER $\mathrm{Ca}^{2+}$ was depleted (Figure 2e) and intracellular $\mathrm{Ca}^{2+}$ levels were significantly increased by exposure to $100 \mathrm{nM}$ SBF-1 in both a concentration- and time-dependent manner (Figure $3 a$ and Supplementary Figure S4). BAPTA (1,2-Bis(o-aminophenoxy)ethane- $N, N, N^{\prime}, N^{\prime}$-tetraacetic acid), a cell-permeant $\mathrm{Ca}^{2+}$ chelator widely used in $\mathrm{Ca}^{2+}$-related study, ${ }^{27,32}$ partially reversed SBF-1-induced proliferation suppression (Figure 3b) and markedly attenuated ER stress induced by SBF-1 (Figures $3 c$ and d) in HeLa cells.

The SERCA2 level controls the sensitivity of HeLa cells to SBF-1. To further demonstrate the role of SERCA2 in the antitumor effects of SBF-1, we stably knocked down SERCA2 in HeLa cells (Supplementary Figures S5a and b), which had no influences on the growth of HeLa cells under normal culture conditions (Supplementary Figure S5c). However, the SERCA2 silence greatly enhanced SBF-1-induced repression of cell growth (Figure $4 a$ ) and migration (Figure 4b). Then, we confirmed that the protein levels of ATF6a (p50) and phospho-elF2 $a^{\text {Ser51 }}$ (Figure 4c), and the mRNA levels of CHOP and GRP78 (Supplementary Figure S6) in HeLa cells with stable SRECA2 knockdown were increased more significantly after exposure to SBF-1, compared with cells with stable NC lentivirus infection. In addition, SERCA2b overexpression had no influences on the growth of HeLa cells under normal culture conditions (Supplementary Figure S7), but partially reduced SBF-1-induced proliferation suppression (Figure $4 d$ ). The increase in protein levels of CHOP by SBF-1 was almost completely blocked in HeLa cells transfected with hSERCA2b as compared with cells transfected with mock vector (Figure $4 \mathrm{e}$ ). The above results indicate that SBF-1 suppresses the HeLa cell growth and migration depending on the activity and level of SERCA2.

SBF-1 inhibits tumor growth at a very low dose in HeLa xenografts with decreased SERCA activity and increased ER stress and apoptosis. To evaluate the antitumor effects of SBF-1 in vivo, we daily intraperitoneally injected vehicle $(0.1 \%$ dimethyl sulfoxide (DMSO) in phosphate-buffered 
a

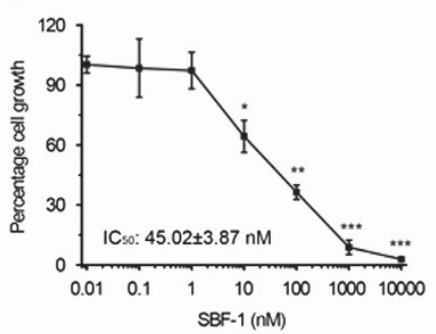

d

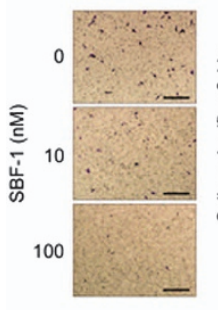

b
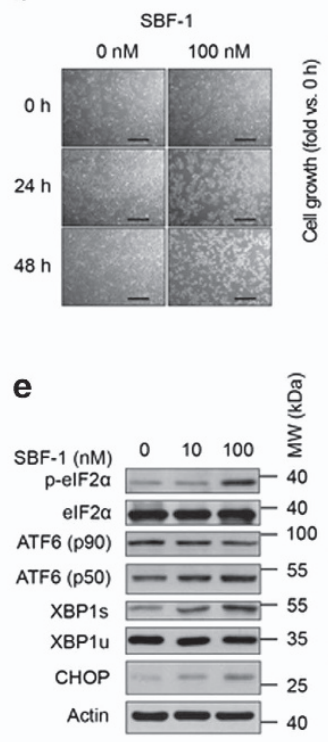

C
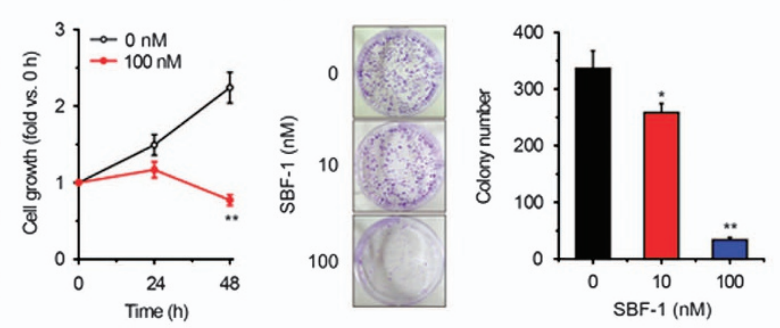

f

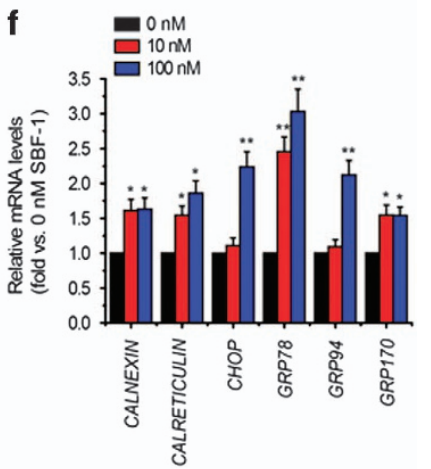

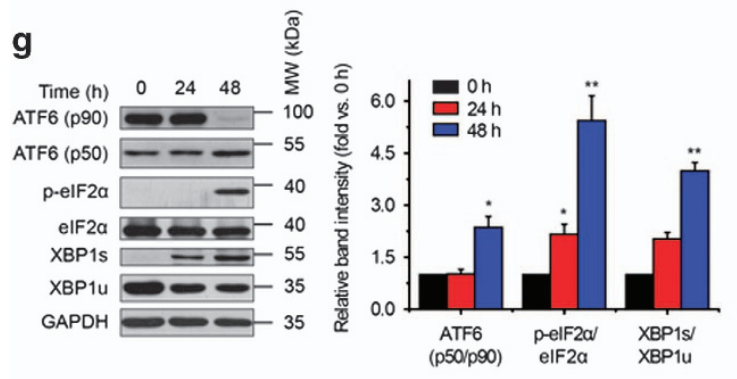

h

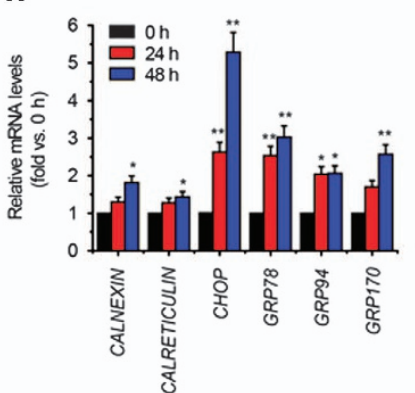

i

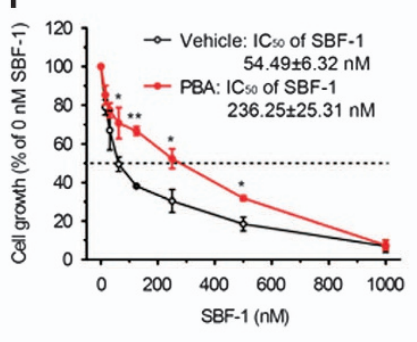

Figure 1 SBF-1 induced ER-stress-associated cell death in human cervical cancer HeLa cells. (a and $\mathbf{b})$ HeLa cells $\left(2 \times 10^{3}\right.$ per well) were seeded into 96 -well plates and incubated with DMSO $(0.1 \%)$ or indicated concentrations of SBF- 1 for indicated time periods. Cell growth was determined by MTT assay. (c and d) HeLa cells $\left(2 \times 10^{5}\right.$ per well) were seeded into six-well plates and incubated with DMSO $(0.1 \%)$ or various concentrations of SBF-1 for $48 \mathrm{~h}$. (c) One thousand viable cells per well were seeded into six-well plates and maintained at $37^{\circ} \mathrm{C}$ for another 2 weeks. Colonies were fixed with $4 \%$ PFA and stained with crystal violet. The number of colonies (>80 cells per colony) was counted under a light microsope. (d) Ten thousand cells (in $0.1 \mathrm{ml}$ serum-free DMEM) were seeded into the inner room of transwells and maintained at $37^{\circ} \mathrm{C}$ for another $24 \mathrm{~h}$. Migrated cells were fixed in $4 \%$ PFA and stained with crystal violet. The number of migrated cells was calculated under a light microscope. (e and f) HeLa cells $\left(2 \times 10^{5}\right.$ per well) were seeded into six-well plates and incubated with DMSO $(0.1 \%)$ or various concentrations of SBF-1 for $48 \mathrm{~h}$. (e) The protein levels of ATF6 $\alpha$ (p90), ATF6 $\alpha$ (p50), phosphorylated elF2 $\alpha{ }^{\text {Ser51 }}, \mathrm{XBP} 1 \mathrm{u}, \mathrm{XBP} 1 \mathrm{~s}$ and CHOP were detected by immunoblotting (left panel), and the relative band intensity was analyzed with Image $\mathrm{J}$ software (NIH, right panel) and normalized with $\beta$-actin. $\beta$-Actin was performed as a loading control. (f) The mRNA levels of CALNEXIN, CALRETICULIN, CHOP, GRP78, GRP94 and GRP170 were detected by quantitative real-time PCR (Q-PCR) and normalized with RN18S. ( $\mathbf{g}$ and $\mathbf{h})$ HeLa cells $\left(2 \times 10^{5}\right.$ per well) were seeded into six-well plates and incubated with DMSO $(0.1 \%)$ or $100 \mathrm{nM}$ SBF-1 for indicated time periods. (g) The protein levels of ATF6 $\alpha$ (p90), ATF6 $\alpha$ (p50), phosphorylated elF2 $\alpha{ }^{\text {Ser51 }}$, XBP1u and XBP1s were detected by immunoblotting (left panel), and the relative band intensity were analyzed with Image $\mathrm{J}$ software (right panel). Glycolytic glyceraldehyde-3-phosphate dehydrogenase (GAPDH) was performed as a loading control. (h) The mRNA levels of CALNEXIN, CALRETICULIN, CHOP, GRP78, GRP94 and GRP170 were detected by Q-PCR and normalized with RN18S. (i) HeLa cells $\left(2 \times 10^{3}\right.$ per well) were seeded into 96 -well plates and incubated with vehicle $(0.2 \%$ DMSO) or PBA $(2.5 \mathrm{mM})$ plus various concentrations of SBF- 1 for $48 \mathrm{~h}$. Then, cell growth was determined by MTT assay. The dotted line showed $50 \%$ cell growth of $0 \mathrm{nM}$ SBF-1. Images shown were representative of three independent experiments. Scale bars, $100 \mu \mathrm{m}$. Data were means \pm S.D. of three independent experiments. ${ }^{*} P<0.05,{ }^{* *} P<0.01$ versus $0 \mathrm{nM} \mathrm{SBF}-1$ (a and $\left.\mathbf{c}-\mathbf{f}\right), 0 \mathrm{~h}(\mathbf{b}, \mathbf{g}$ and $\mathbf{h})$ or vehicle (i). MW, molecular weight

saline (PBS)) or $5 \mu \mathrm{g} / \mathrm{kg}$ SBF-1 to tumor-bearing nude mice. Changes in tumor volumes and body weight were measured and recorded every 2 days. The growth of HeLa xenografts was significantly inhibited after 8 days of administration of SBF-1, in comparison with vehicle-treated group (Figure 5a). The tumor mass and the percentage of tumor weight in body weight was significantly decreased by SBF-1 treatment (Figure 5b), whereas body weight was not influenced (Supplementary Figure S8). Furthermore, the expression of proliferating cell nuclear antigen (PCNA) (Figure $5 \mathrm{c}$ ) and antigen Ki-67 (Figure 5d) was significantly inhibited by SBF-1. In contrast, the percentage of terminal deoxynucleotidyl transferase dUTP nick-end labeling (TUNEL)-positive cells was markedly increased in SBF-1-treated xenografts (Figure 5e). As expected, in this case, the SERCA activity of tumor xenografts was significantly inhibited by SBF-1 (Figure 5f), with increased SERCA2 protein level and unchanged mRNA level (Supplementary Figure S9). 


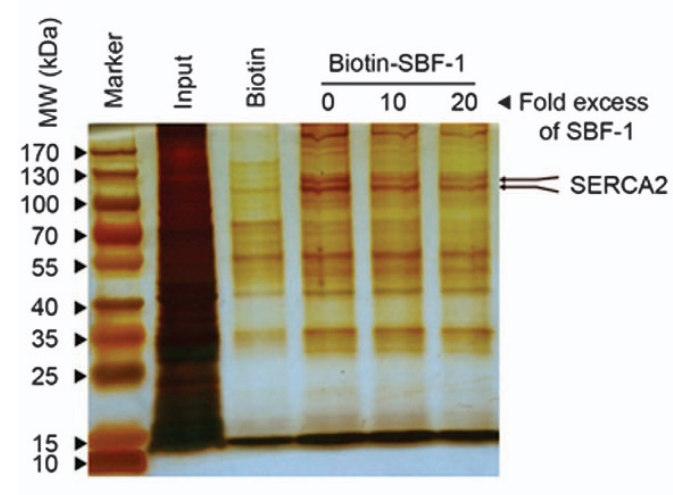

b

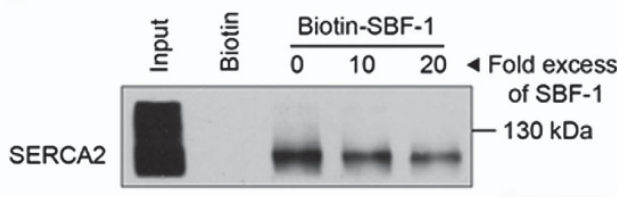

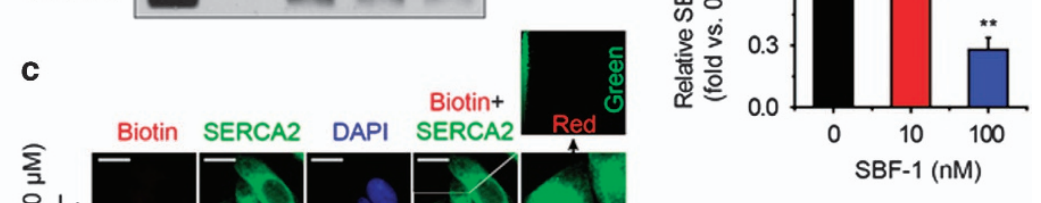

e $10 \mu \mathrm{M}$ TG added at $100 \mathrm{~s}$
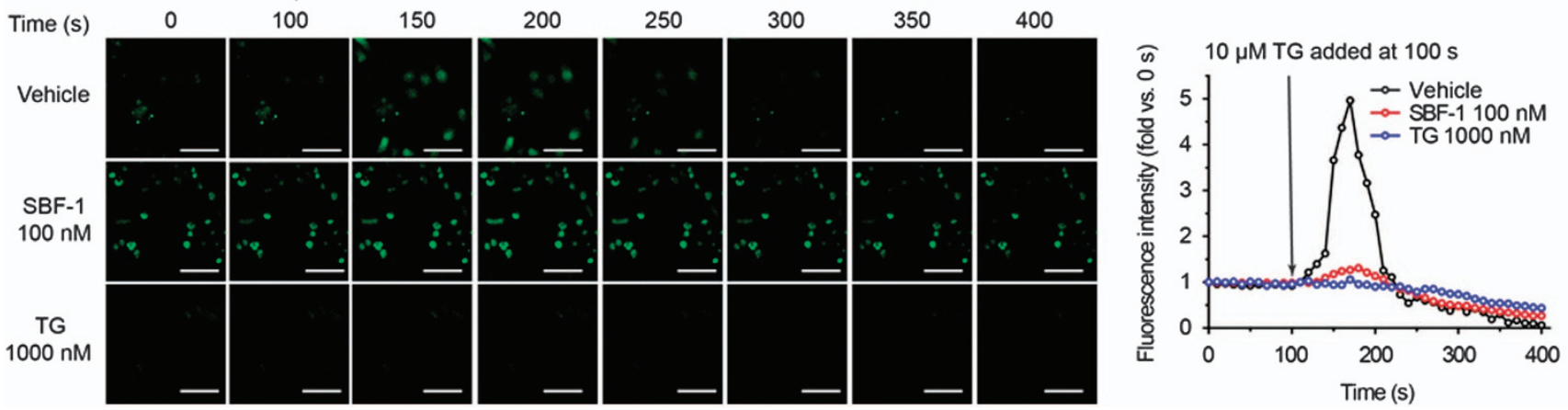

Figure 2 SBF-1 bound to SERCA2 and caused depletion of ER Ca ${ }^{2+}$ in HeLa cells. (a and $\mathbf{b}$ ) HeLa whole-cell lysates were incubated with biotin (10 $\mu$ M), biotin-SBF-1 $(10 \mu \mathrm{M})$, biotin-SBF-1 $(10 \mu \mathrm{M})$ plus SBF-1 $(100 \mu \mathrm{M})$ or biotin-SBF-1 $(10 \mu \mathrm{M})$ plus SBF-1 $(200 \mu \mathrm{M})$, and streptavidin-conjugated sepharose beads. (a) The proteins bound to the beads were separated with SDS-PAGE and stained with silver nitrate. The arrows indicated the interested protein bands analyzed by LC/MS. (b) The proteins bound to the beads were separated with SDS-PAGE and immunoblotted with anti-SERCA2 antibody. (c) HeLa cells were seeded on glass slides and incubated with DMSO (0.1\%) or biotin-SBF-1 $(10 \mu \mathrm{M})$ for $10 \mathrm{~min}$. Then, the cells were fixed in 4\% PFA and stained with anti-biotin and anti-SERCA2 antibodies. Red, green and blue color indicated the location of biotin, SERCA2 and nucleus, respectively. The yellow color indicated the colocalization of biotin-SBF-1 and SERCA2. Scale bars, $5 \mu \mathrm{m}$. The colocalization rate was analyzed with Image Pro Plus 6.0 software. (d) HeLa cells pretreated with DMSO $(0.1 \%)$ or various concentrations of SBF- 1 for $48 \mathrm{~h}$ were washed once with cold saline $(0.9 \% \mathrm{NaCl})$ and lysed with pulse sonication. Then, SERCA activity was measured and normalized with DMSO-treated cells (SERCA activity of DMSO-treated cells was $1.66 \pm 0.22 \mu \mathrm{mol} / \mathrm{mg} \mathrm{protein} \mathrm{per} \mathrm{h}$ ). ${ }^{\star} P<0.05,{ }^{\star \star} P<0.01$ versus $0 \mathrm{nM}$ SBF-1. (e) HeLa cells pretreated with vehicle (0.1\% DMSO), SBF-1 (100 nM) or thapsigargin (TG, $\left.1 \mu \mathrm{M}\right)$ were stained with Fluo-4 AM $(2.5 \mu \mathrm{M})$. Fluorescence signals were acquired under a mercury lamp (Olympus). Photos were taken every $10 \mathrm{~s}$ and $10 \mu \mathrm{M}$ TG was added at $100 \mathrm{~s}$ when the signals were stable. Fluorescence intensity was analyzed with Image Pro Plus 6.0 software (Media Cybernetics) and normalized with the intensity of $0 \mathrm{~s}$. Scale bars, $40 \mu \mathrm{m}$. Images shown were representative of three independent experiments

Meanwhile, the protein levels of XBP1s, ATF6a (p50), phospho-elF2 $\alpha^{\text {Ser51 }}$ and CHOP (Figure $5 \mathrm{~g}$ ), and the percentage of CHOP-positive cells (Figure $5 \mathrm{~h}$ ) were significantly increased in SBF-1-treated xenografts, as compared with vehicle-treated xenografts.

SERCA2 positively correlates with the malignant progress of human cervical cancer. To evaluate the relationship between SERCA2 and malignance of cervical cancer, the protein level of SERCA2 was detected by immunohistochemistry in tissue arrays of human cervical cancer. Modest SERCA2 expression was detected in normal cervix tissues $(n=9)$ and cancer adjacent normal cervix tissue (NAT, $n=14$ ). Comparably, a significantly elevated SERCA2 expression was detected in malignant tumor tissues (carcinoma, $n=299$ ) and lymph node metastasis (metastasis, $n=8$ ) (Figures $6 a$ and c; one-way analysis of variance
(ANOVA), $P<0.0001$ ), and such expression among 299 samples (stage I, $n=171$; stage II, $n=83$; stage III, $n=45$ ) was increased along with the clinical stages of carcinoma (Figures $6 \mathrm{~b}$ and $\mathrm{c}$; one-way ANOVA, $P=0.0013$ ). These results indicate that SERCA2 has a positive correlation with the malignance of human cervical cancer and could be a therapeutic target for cervical cancer therapy.

\section{Discussion}

Cervical cancer is the most common life-threatening disease among women worldwide, and the therapeutic effects are bleak because of recurrence and chemoresistance. ${ }^{24}$ Thus, it is significant to search for effective targets for the treatment of cervical cancer. In the present study, we found that low concentrations of SBF-1 (10 and $100 \mathrm{nM})$ significantly inhibited the growth, migration and colony formation of HeLa 
a
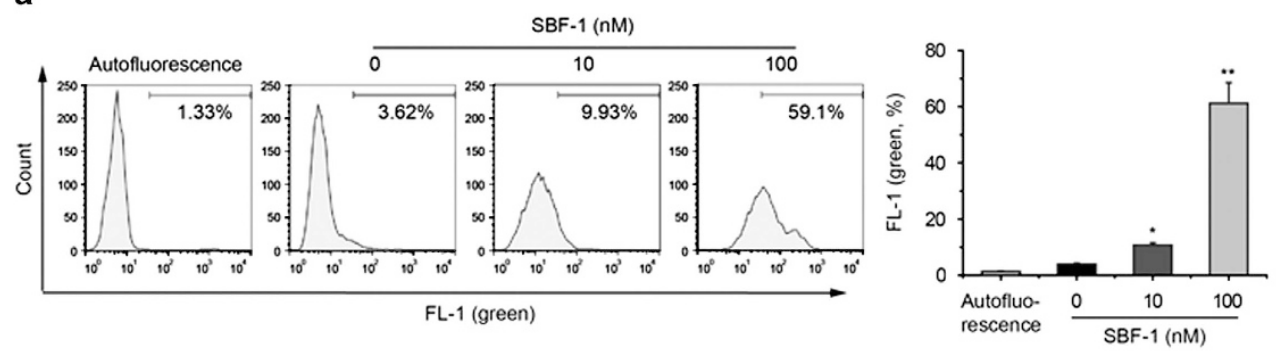

d

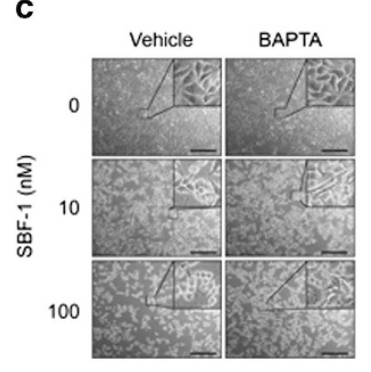

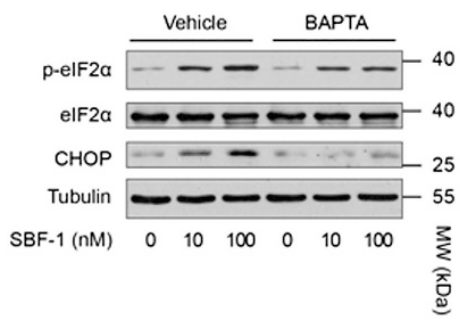
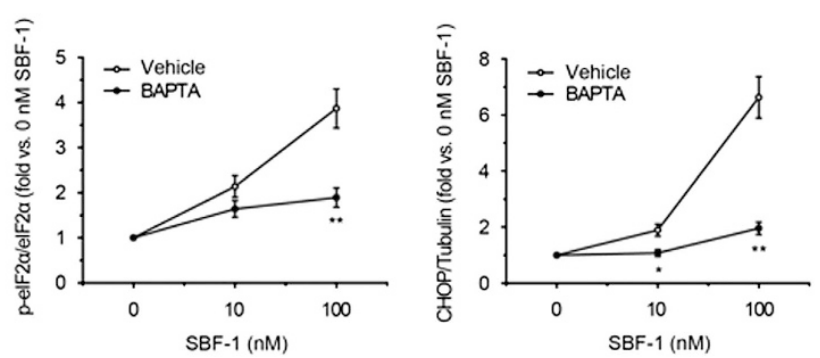

Figure 3 ER stress induced by SBF-1 was partially dependent on the increase of cytosolic $\mathrm{Ca}^{2+}$. (a) HeLa cells pretreated with DMSO $(0.1 \%)$ or various concentrations of SBF-1 for $48 \mathrm{~h}$. Then, the cells were stained with Fluo-4 AM $(2.5 \mu \mathrm{M})$. Percentage of Fluo-4-positive cells was analyzed with FACS. (b) HeLa cells $\left(2 \times 10^{3}\right.$ per well) were seeded into $96-$ well plates and incubated with vehicle $(0.1 \%$ DMSO) or $10 \mu \mathrm{M}$ BAPTA-am for $1 \mathrm{~h}$. Then, the cells were incubated with DMSO $(0.1 \%)$ or various concentrations of SBF- 1 for another $48 \mathrm{~h}$. Cell growth was determined by MTT assay. The dotted line indicated 50\% cell growth of $0 \mathrm{nM} \mathrm{SBF-1.} \mathrm{(c} \mathrm{and} \mathrm{d)} \mathrm{HeLa} \mathrm{cells} \mathrm{were} \mathrm{seeded} \mathrm{into} \mathrm{six-well} \mathrm{plates} \mathrm{and}$ incubated with vehicle $(0.1 \%$ DMSO) or BAPTA-am $(10 \mu \mathrm{M})$ for $1 \mathrm{~h}$. Then, the cells were incubated with DMSO $(0.1 \%)$ or various concentrations of SBF- 1 for $48 \mathrm{~h}$. (c) Photos produced by phase contrast microscope were shown. (d) The protein levels of phosphorylated elF2 $\alpha^{\text {Ser51 }}$, total elF2 $\alpha$ and $\mathrm{CHOP}$ were detected by immunoblotting (left panel), and the relative band intensity was analyzed with Image $\mathrm{J}$ software and normalized with $\alpha$-tubulin (middle and right panels). $\alpha$-Tubulin was performed as a loading control. Images shown were representative of more than three independent experiments. Data were means \pm S.D. of more than three independent experiments. Scale bars, $100 \mu \mathrm{m}$. ${ }^{*} P<0.05$, ${ }^{\star *} P<0.01$ versus 0 nM SBF-1 (a) or vehicle $(\mathbf{b}-\mathbf{d})$

cells, a popularly used human cervical cancer cell line (Figures $1 \mathrm{a}-\mathrm{d})$. ER stress is a well-known reason for cell death. ${ }^{33}$ SBF-1 induced ER stress and UPR responses in a concentration- and time-dependent manner, and the chemical chaperone PBA partially reversed the antigrowth activity of SBF-1 (Figures 1e-i). Compared with slowly dividing cells, rapidly dividing cancer cells are more sensitive to ER stress inducers, because of the high levels of protein folding. ${ }^{2}$ Compared with naive T lymphocytes and ECV304 cells (slowly dividing cells), Jurkat and HeLa cells (rapidly dividing cancer cells) were more sensitive to SBF-1 (Figure 1a and Supplementary Figure S11), suggesting that SBF-1 antigrowth effects is not due to general cytotoxicity.

High concentrations of $\mathrm{Ca}^{2+}$ in ER lumen are essential for ER folding capacity. ${ }^{34}$ SERCA is a pump to transport $\mathrm{Ca}^{2+}$ from the cytoplasm to ER lumen, ${ }^{11,12}$ and inhibition of SERCA activity impairs ER $\mathrm{Ca}^{2+}$ homeostasis and causes severe ER stress. ${ }^{34-37}$ SERCA2, the major SERCA isoform of HeLa cells, was found to bind with SBF-1, and SERCA activity was suppressed by SBF-1 (Figures 2a-d). Accordingly, SBF-1 depleted $\mathrm{ER} \mathrm{Ca}^{2+}$ and increased intracellular $\mathrm{Ca}^{2+}$ levels, and $\mathrm{Ca}^{2+}$ chelator BAPTA partially reversed SBF-1-induced ER stress and growth suppression (Figures $2 e$ and 3). Interestingly, the baseline $\mathrm{Ca}^{2+}$ levels in SBF-1-treated cells were obviously higher than those in TG-treated cells (Figure 2e), suggesting the differences between SBF-1 and TG. It is well known that TG is a specific SERCA inhibitor, which depletes $\mathrm{ER} \mathrm{Ca}^{2+}$ quickly. ${ }^{27}$ After incubation with TG for $48 \mathrm{~h}, \mathrm{ER} \mathrm{Ca}^{2+}$ was almost completely depleted and exhausted. However, there was still abundant cytosolic $\mathrm{Ca}^{2+}$, and a small quantity of $\mathrm{ER} \mathrm{Ca}^{2+}$ in SBF-treated cells. As shown in Figure 2c, the colocalization rate of SBF-1 and SERCA2 was $\sim 60 \%$, indicating that SBF-1 also bound to other proteins, which was supported by the competitive binding assay (Figure 2a). LC/MS identified many other proteins, including plasma membrane calcium-transporting ATPase 1 (PMCA1, data not shown). Moreover, SBF-1 started to increase the baseline cytosolic $\mathrm{Ca}^{2+}$ levels after $3-\mathrm{h}$ incubation (Supplementary Figure S4) and did not induce cytosolic $\mathrm{Ca}^{2+}$ exhaustion, which was quite different from TG. Combined with these data, we supposed that SBF-1 might inhibit the activity of SERCA and $\mathrm{Ca}^{2+}$ pumps in the plasma membrane (such as PMCA1), resulting in $\mathrm{Ca}^{2+}$ release from $\mathrm{ER}$ and accumulation in the cytoplasm, which might explain the strong antigrowth effects of SBF-1.

It has been reported that impairment of SERCA2 levels increase the sensitivity of cells to ER stress. ${ }^{19,34,38,39}$ Coincidentally, knockdown of SERCA2 increased the sensitivity of HeLa cells to SBF-1, whereas overexpression of SERCA2 decreased the sensitivity of HeLa cells to SBF-1 (Figure 4 and Supplementary Figure S7). Furthermore, in vivo experiments indicated that a very low dose of SBF-1 $(5 \mu \mathrm{g} / \mathrm{kg})$ markedly inhibited the growth of HeLa xenografts, with repression of SERCA activity and induction of abundant apoptosis and severe ER stress (Figure 5 and Supplementary Figure S9).

Aberrant SERCA expression has been reported to be relevant with the susceptibility and progression of colon 


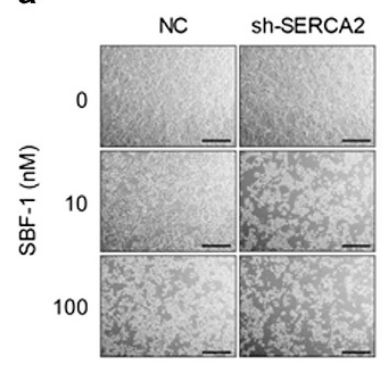

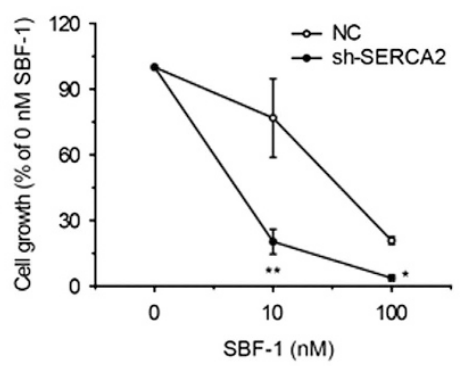

b

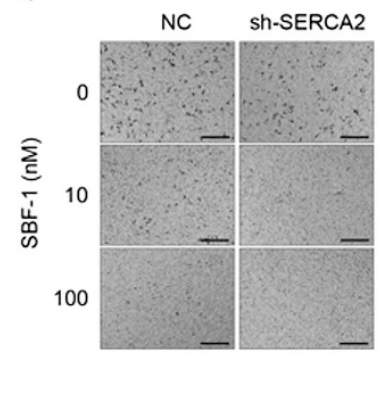

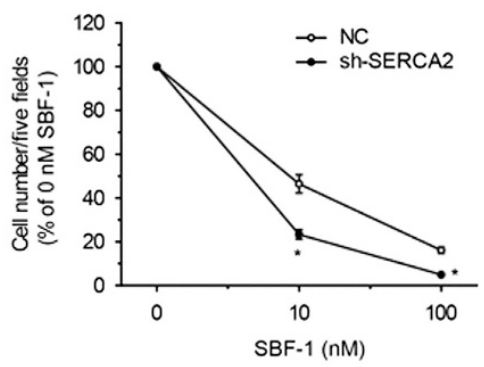

C
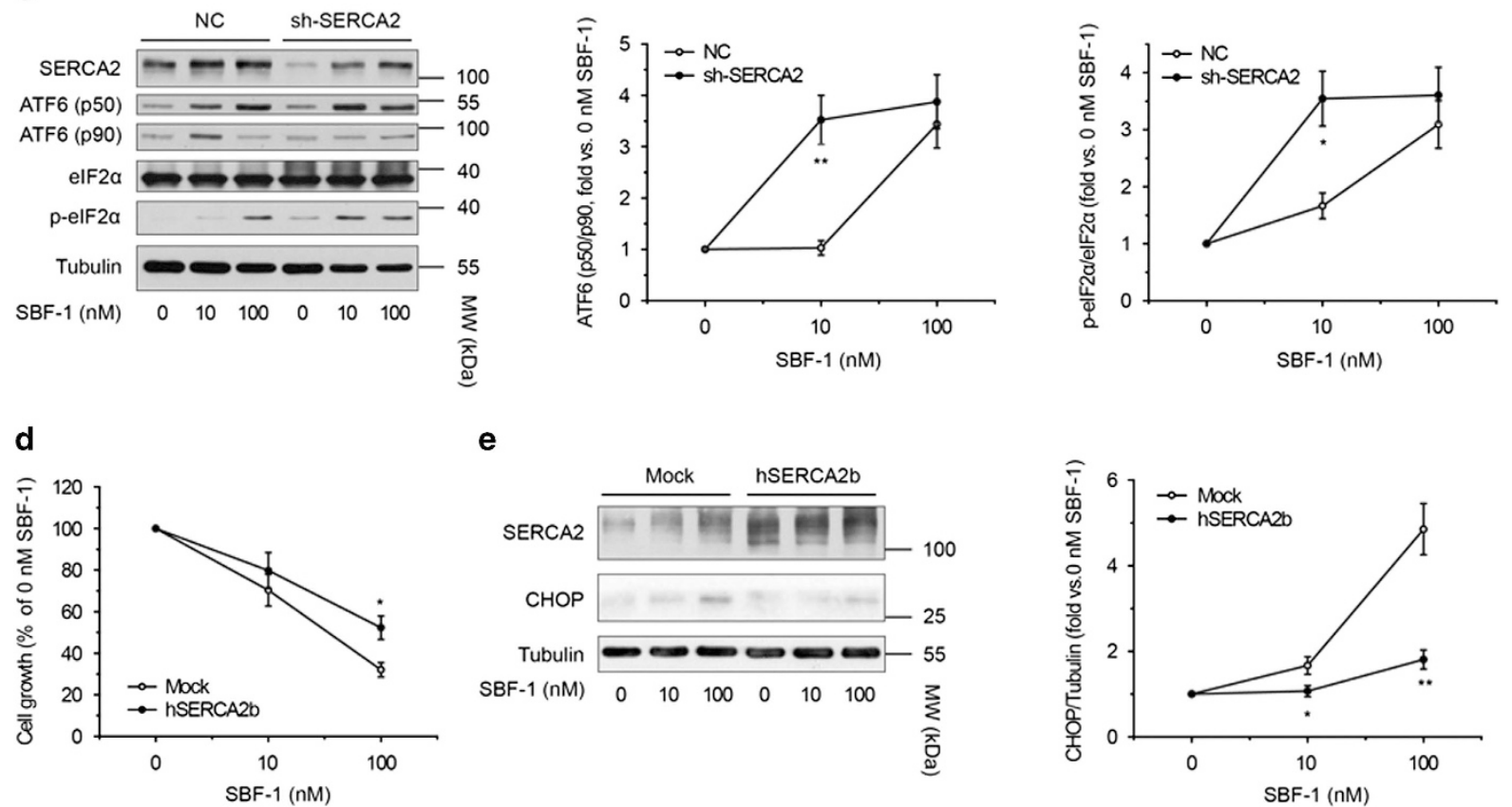

Figure 4 SERCA2 level controlled the sensitivity of HeLa cells to SBF-1. (a-c) HeLa cells stably infected with NC shRNA and SERCA2 shRNA were incubated with DMSO $(0.1 \%$ ) or various concentrations of SBF- 1 for $48 \mathrm{~h}$. (a) Representative images of cell growth of three independent experiments were shown. Scale bars, $100 \mu \mathrm{m}$. Cell number was counted by Typan blue staining and normalized with O nM SBF-1. (b) Ten thousand viable cells (in $0.1 \mathrm{ml}$ serum-free DMEM) were seeded into the inner rooms of transwells and maintained at $37^{\circ} \mathrm{C}$ for another $24 \mathrm{~h}$. Migrated cells were fixed, stained with crystal violet and counted under a light microscope. Representative images of three independent experiments were shown (left panel). Scale bars, $100 \mu \mathrm{m}$. The number of migrated cells was counted with Image J software (right panel). (c) The protein levels of SERCA2, ATF6 $\alpha$ (p90), ATF6 $\alpha$ (p50), total elF2 $\alpha$ and phosphorylated elF2 $\alpha$ were detected by immunoblotting (left panel), and the relative band intensity was analyzed with Image $J$ software and normalized with $\alpha$-tubulin (middle and right panels). $\alpha$-Tubulin was performed as a loading control. (d and e) HeLa cells transiently transfected with mock or hSERCA2b for $48 \mathrm{~h}$ were incubated with various concentrations of SBF-1 for $48 \mathrm{~h}$. (d) Cell growth was determined by Trypan blue staining and normalized with DMSO-treated cells. (e) The protein levels of SERCA2 and CHOP were detected by immunoblotting (left panel), and the relative band intensity was analyzed with Image $\mathrm{J}$ software and normalized with $\alpha$-tubulin (right panel). $\alpha$-Tubulin was performed as a loading control. Images shown were representative of three independent experiments. Data were means \pm S.D. of three independent experiments. ${ }^{*} P<0.05,{ }^{* \star} P<0.01$ versus $\mathrm{NC}$ (a-c) or mock (d and e). NC, negative control

cancer, lung cancer and liposarcoma. ${ }^{13-21}$ However, the correlation of SERCA2 with the malignance of cervical cancer is not reported before. The following experiments indicated that elevated SERCA2 expression was detected in malignant cervical carcinomas and lymph metastasis, with a positive correlation with the clinical stages of malignant cervical carcinomas (Figures 6a-c).

In all, as illustrated in Figure $6 \mathrm{~d}$, when cells are exposed to SBF-1, SERCA activity is suppressed, inducing depletion of $\mathrm{ER} \mathrm{Ca}^{2+}$ and increase of cytosolic $\mathrm{Ca}^{2+}$, which disturbs ER folding capacity and increases unfolded and misfolded proteins, activating the signaling pathways of UPR response and causing ER stress-associated cell death. This study suggests that SERCA2 could be a therapeutic target in human cervical cancer and SBF-1 might be a novel SERCA inhibitor to induce cell death.

\section{Materials and Methods}

Materials. SBF- 1 is a synthetic steroidal glycoside. ${ }^{30}$ For in vitro experiments, SBF-1 was dissolved in DMSO to a concentration of $20 \mathrm{mM}$ (stock solution), and biotin-SBF-1 was dissolved in DMSO to a concentration of $10 \mathrm{mM}$ (stock solution); for in vivo assay, SBF-1 was dissolved in DMSO to a concentration of $1 \mathrm{mg} / \mathrm{ml}$ (stock solution), and stored at $-20^{\circ} \mathrm{C}$. Anti-phospho-elF2 $\alpha$ (no. 3597), anti-elF2 $\alpha$ (no. 9722), anti-CHOP (no. 5554) and anti-SERCA2 (no. 9580) antibodies were purchased from Cell Signaling Technology (Beverly, MA, USA). Anti-ATF6 $\alpha$ (sc-22799), anti-PCNA (sc-56), anti-Ki-67 (sc-15402), anti-GAPDH (sc-166545), anti- $\beta$-actin (sc-47778) antibodies, goat anti-mouse IgG, goat anti-rabbit IgG and 
a
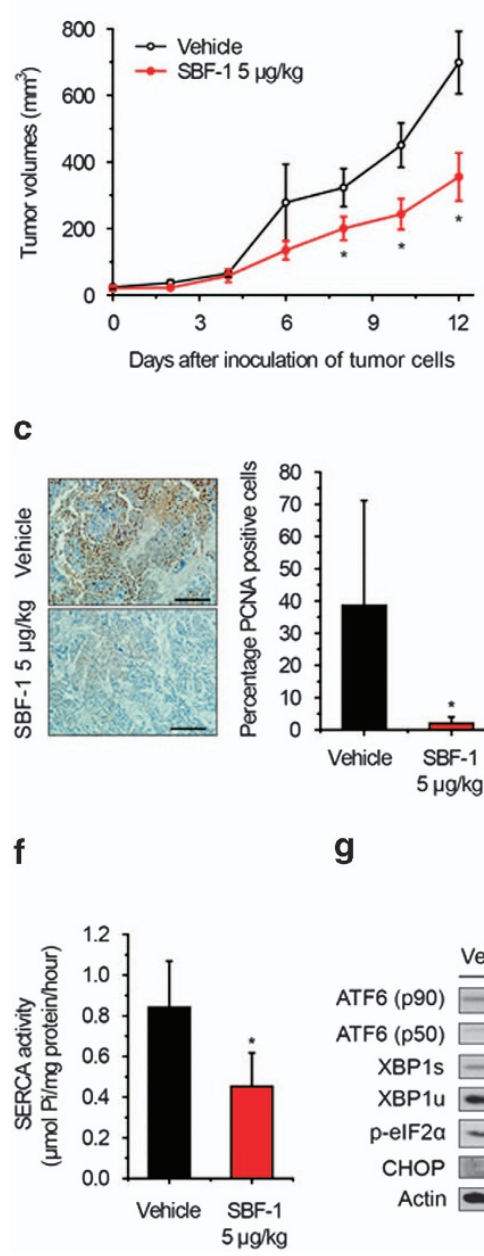

C
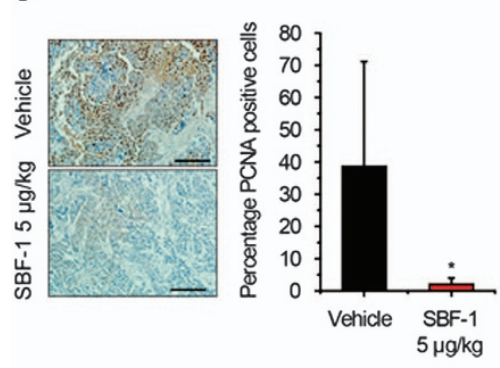

b
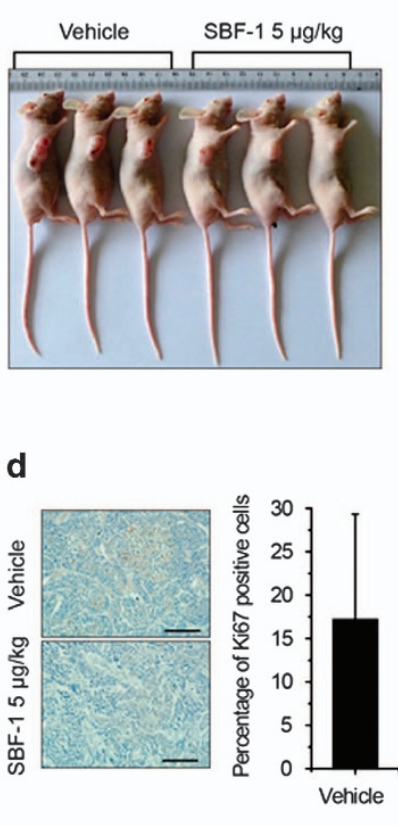
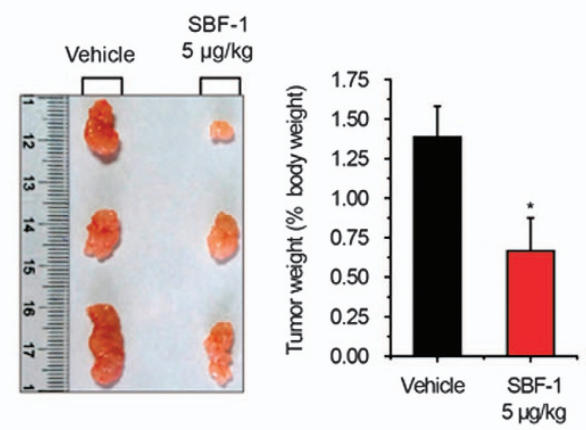

d

g

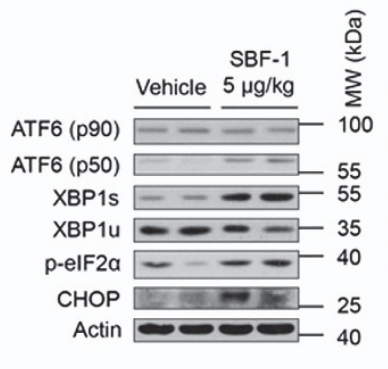

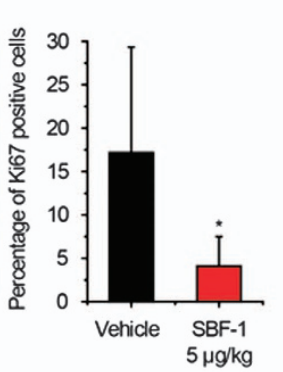

e

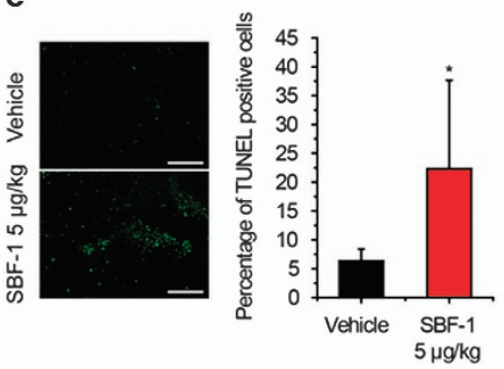

h

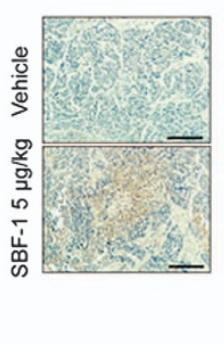

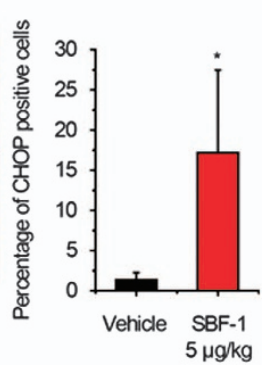

Figure 5 SBF-1 suppressed tumor growth of HeLa xenografts in nude mice. One million cells (in $0.1 \mathrm{ml}$ PBS) were injected subcutaneously into the right flanks of female nude mice ( $6-8$ weeks old). One week after the inoculation, all the mice formed visible tumors and were distributed into two groups. Vehicle $(0.1 \mathrm{DMSO}$ in PBS, $n=5)$ and $5 \mu \mathrm{g} / \mathrm{kg}$ SBF-1 $(n=6)$ were intraperitoneally injected into the mice. (a) Tumor volumes of the mice. (b) Three representative mice per group were shown (left panel). Three representative tumors were shown (middle panel), and the percentage of tumor weight in body weight was calculated (right panel). (c) The protein level of PCNA was detected with immunohistochemistry. Representative images of six mice were shown (left panel), and the percentage of PCNA-positive cells was calculated (right panel). (d) The protein level of Ki-67 was detected by immunohistochemistry. Representative images of six mice were shown (left panel), and the percentage of Ki-67-positive cells was calculated (right panel). (e) Apoptosis in tumor sections was detected with TUNEL staining. Representative images of six mice were shown (left panel), and the percentage of TUNEL-positive cells was calculated (right panel). (f) SERCA activity of vehicle- and SBF-1-treated xenografts. (g) The protein levels of ATF6 $\alpha$ (p90), ATF6 $\alpha$ (p50), XBP1s, XBP1u, phosphorylated elF2 $\alpha$ and $\mathrm{CHOP}$ were detected by immunoblotting (left panel), and the relative band intensity was analyzed with Image $\mathrm{J}$ software and normalized with $\beta$-actin (right panel). Blots shown were representative of six mice. (h) The protein level of $\mathrm{CHOP}$ was detected by immunohistochemistry. Representative images of six mice were shown (left panel), and the percentage of CHOP-positive cells was calculated (right panel). Scale bars, $50 \mu \mathrm{m}$. Data were means \pm S.D. of six mice. ${ }^{*} P<0.05,{ }^{* *} P<0.01$ versus vehicle

donkey anti-goat IgG HRP- conjugated antibodies and mouse, rabbit and goat IgG were purchased from Santa Cruz Biotechnology (Santa Cruz, CA, USA). Anti-XBP1 (no. 3166-1) and anti- $\alpha$-tubulin (no. 1878-1) antibodies were purchased from Epitomics - an Abcam Company (Burlingame, CA, USA). Tissue arrays of human cervical cancer (CR2088, CR805 and CR806) were purchased from US Biomax Inc. (Rockville, MD, USA). Fibronectin (F2006) and PBA were purchased from Sigma Chemical Co. (St. Louis, MO, USA). Fluo-4 AM (F14217), BAPTA-am (B1205), Alexa Fluor 488 donkey anti-goat $\lg G(H+L)(A 11055)$ and Alexa Fluor 594 goat anti-mouse $\lg G(H+L)(A 11005)$ were purchased from Life Technologies (Carlsbad, CA, USA). 3-(4, 5-Dimethylthiazol-2-yl)-2,5-diphenyltetrazolium bromide (MTT) and DMSO were purchased from Sunshine Biotechnology (Nanjing, China). All other chemicals were purchased from Sigma Chemical Co.

Cell culture. Human cervical cancer cell line HeLa, human umbilical vein endothelial cell line ECV304 and human T-lymphocyte cell line Jurkat were purchased from the Shanghai Institute of Cell Biology (Shanghai, China), respectively, maintained in Dulbecco's modified Eagle's medium (DMEM; Gibco, Grand Island, NY, USA) or in RPMI-1640 medium (Gibco) supplemented with $10 \%$ fetal bovine serum (FBS; Gibco), $100 \mathrm{U} / \mathrm{ml}$ penicillin and $100 \mathrm{mg} / \mathrm{ml}$ streptomycin, and incubated at $37^{\circ} \mathrm{C}$ in a humidified atmosphere containing $5 \% \mathrm{CO}_{2}$ in the air. Mouse $\mathrm{T}$ lymphocytes were separated from peripheral lymph nodes of C57BL/6 mice and maintained in RPMI-1640 medium (Gibco) supplemented with $10 \%$ FBS.

Animals. Female C57BL/6 mice and female nude mice (6-8 weeks old) were obtained from the Shanghai Laboratory Animal Center (Shanghai, China). Briefly, mice were fed with free access to pellet food and water in plastic cages at $21 \pm 2^{\circ} \mathrm{C}$ and kept on a 12-h light-dark cycle. Animal welfare and experimental procedures were carried out strictly in accordance with the Guide for the Care and Use of Laboratory Animals (The Ministry of Science and Technology of China, 2006) and 
a

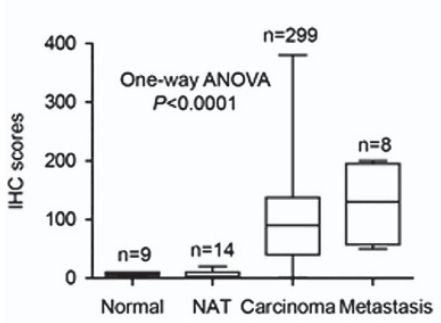

b

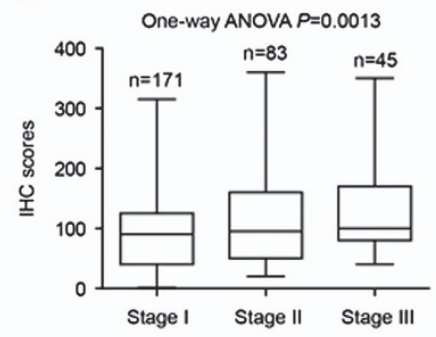

d

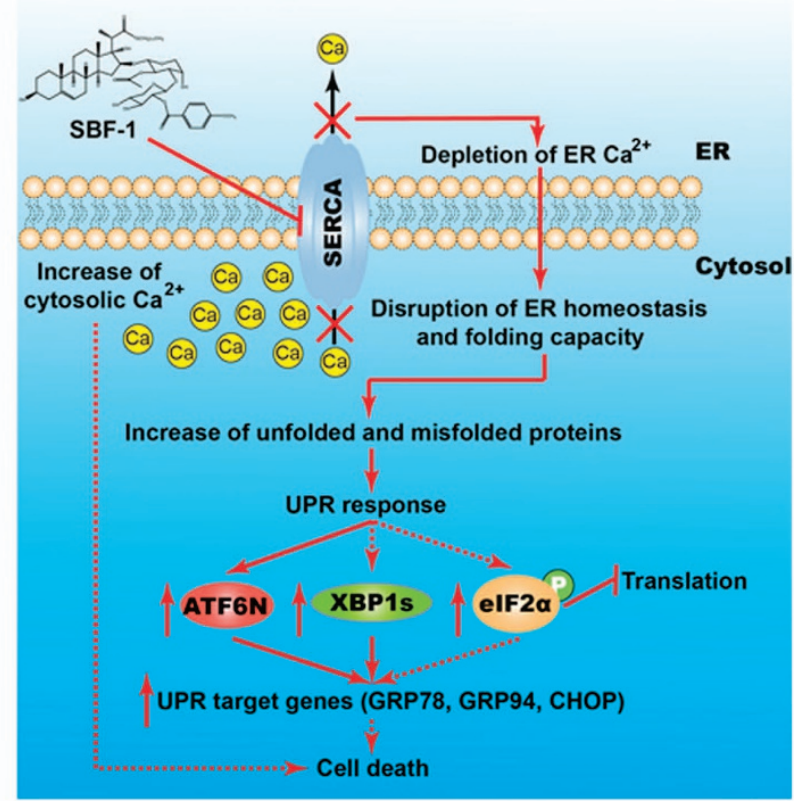

Figure 6 SERCA2 was correlated with the malignance of human cervical cancer. The protein level of SERCA2 in the tissue arrays of normal cervix tissues (normal), cancer adjacent normal cervix tissue (NAT), malignant cervical cancer tissues of different clinical stages (carcinoma, stages I-III) and lymph node metastasis from uterine cervix (metastasis) was detected by immunohistochemistry (IHC). Then, IHC scores were evaluated as shown in Supplementary Figure S10, and the variance was analyzed with oneway ANOVA. (a) IHC scores for normal tissues, NAT, carcinoma and metastasis. (b) IHC scores for different clinical stages of human cervical cancer. (c) Representative images of normal tissues, NAT, different stages of carcinomas and lymph metastasis. Scale bars, $40 \mu \mathrm{m}$. (d) Illustration for the mechanism underlying the anticervical cancer effects of SBF-1. When cells are exposed to SBF-1, SERCA activity is suppressed, inducing depletion of $\mathrm{ER} \mathrm{Ca}^{2+}$ and increase of cytosolic $\mathrm{Ca}^{2+}$, which disturbs ER folding capacity and increases unfolded and misfolded proteins, activating the signaling pathways of UPR response and causing ER stress-associated cell death. ATF6N, N terminal of ATF6 $\alpha$

the related ethical regulations of our university. All efforts were made to minimize animal suffering and to reduce the number of animals used.

MTT assay. A total of $2 \times 10^{3}$ cells were seeded into 96-well plates, and incubated with various concentrations of SBF- 1 at $37^{\circ} \mathrm{C}$ for indicated time periods. Four hours before measurement, $20 \mu \mathrm{l}$ per well MTT solutions $(4 \mathrm{mg} / \mathrm{ml}$ in PBS) were added into the 96-well plates. After incubation at $37^{\circ} \mathrm{C}$ for $4 \mathrm{~h}$, the supernatants were discarded and $200 \mu \mathrm{l}$ per well DMSO was added. Then, the plates were measured under an FL $\times 800$ Fluorescence Microplate Reader (BioTek, Winooski, VT, USA) at $570 \mathrm{~nm}$. The optical density values of the wells without SBF-1 were considered as $100 \%$ cell growth rate.

Migration and colony formation assay. A total of $2 \times 10^{5}$ cells per well were seeded into 6-well plates and incubated with DMSO or various concentrations of SBF-1 for $48 \mathrm{~h}$. For migration assay, the cells were washed once with serum-free DMEM and diluted to a concentration of $1 \times 10^{5}$ per $\mathrm{ml}$, and $0.1 \mathrm{ml}$ cell suspension was added to the inner room of transwell (Costar) pretreated with $10 \mu \mathrm{g} / \mathrm{ml}$ fibronectin. Next, $0.6 \mathrm{ml}$ DMEM supplanted with $20 \%$ FBS was added into the wells of 24-well plates and the cells were incubated at $37^{\circ} \mathrm{C}$ for another $24 \mathrm{~h}$. Then, the cells were fixed with $4 \%$ paraformaldehyde (PFA) at room temperature for 30 min and stained with crystal violet (Sigma; $1 \%$ in distilled water) for $10 \mathrm{~min}$. After washing two times with distilled water, migrated cells were counted with an optical microscope (Olympus, Shinjuku, Tokyo, Japan; five fields per transwell). For colony formation assay, $1 \times 10^{3}$ cells per well were seeded into 6-well plates and incubated at $37^{\circ} \mathrm{C}$ for another 2 weeks. Then, the cells were fixed with $4 \%$ paraformaldehyde at room temperature for $30 \mathrm{~min}$ and stained with crystal violet for $10 \mathrm{~min}$ ( $1 \%$ in distilled water). After washing two times with distilled water, photos were taken with a digital camera (Olympus), and the number of colonies, the cell number of which exceeded 80 , were counted with an optical microscope (Olympus).

Immunoblotting. In brief, cells were collected and washed with ice-cold PBS two times before being lysed in radio immunoprecipitation assay (RIPA) lysis buffer (Beyotime, Haimen, China; $50 \mathrm{mM}$ Tris (pH 7.4), $150 \mathrm{mM} \mathrm{NaCl}, 1 \%$ Triton X-100,
$1 \%$ sodium deoxycholate, $0.1 \%$ SDS, $1 \mathrm{mM}$ phenylmethylsulfonylfluoride, $0.15 \mathrm{U} / \mathrm{ml}$ aprotinin and $1 \mathrm{mg} / \mathrm{ml}$ pepstatin). Whole-cell lysates were collected and proteins were resolved by SDS-PAGE and were then electrotransferred onto polyvinylidene fluoride membranes. Then, the membranes were blocked in $5 \%$ bovine serum albumin (Sigma) at room temperature for $1 \mathrm{~h}$, and the blots were incubated with primary antibody at $4^{\circ} \mathrm{C}$ overnight and with secondary antibody at room temperature for $1 \mathrm{~h}$. After extensive washing, the blots were developed with a chemiluminescence assay system (Cell Signaling Technology) and exposed to films (Kodak, Rochester, NY, USA) for appropriate time periods. The densitometry of immunoblots was quantified with Image $\mathrm{J}$ software (NIH, Bethesda, MD, USA) and normalized with loading controls.

Reverse transcription and quantitative real-time PCR. Total RNA was extracted from cells or animal tissues using Trizol reagent (Life Technologies) according to the manufacturer's instructions. The reverse transcription with $1 \mu \mathrm{g}$ of total RNA was conducted under the following conditions: $42^{\circ} \mathrm{C}$ for $20 \mathrm{~min}$ and $99^{\circ} \mathrm{C}$ for $5 \mathrm{~min}$. The abundance of gene expression was then analyzed with SsoFast EvaGreen Supermix (Bio-Rad, Berkeley, CA, USA) on CFX96 Touch Real-Time PCR Detection System (Bio-Rad; $94^{\circ} \mathrm{C}, 15 \mathrm{~s} ; 58^{\circ} \mathrm{C}, 30 \mathrm{~s} ; 40$ cycles) and normalized with 18 S ribosome RNA (RN18S) level. The primer sequences used were as follows $\left(5^{\prime}-3^{\prime}\right)$ : CALNEXIN - sense, CCAAGGTTACTTACAAAGCTCCA and antisense, GGCCCGAGACATCAACACA; CALRETICULIN - sense, CCTGC CGTCTACTTCAAGGAG and antisense, GAACTTGCCGGAACTGAGAAC; CHOP sense, GGAAACAGAGTGGTCATTCCC and antisense, CTGCTTGAGCCGTTCA TTCTC; GRP78 - sense, CATCACGCCGTCCTATGTCG and antisense, CGTC AAAGACCGTGTTCTCG; GRP94 - sense, GCTGACGATGAAGTTGATGTGG and antisense - CATCCGTCCTTGATCCTTCTCTA; GRP170 - sense, GAGGAGG CGAGTCTGTTGG and antisense, GCACTCCAGGTTTGACAATGG; SERCA1 sense, GTGATCCGCCAGCTAATG and antisense, CGAATGTCAGGTCCGTCT; SERCA2a - sense, CTGTCCATGTCACTCCACTTCC and antisense, TTACTCCA GTATTGCAGGT; SERCA2b - sense, ACCAAATCCTGCTCGTTC and antisense, ATCGCTAAAGTTAGTGTCTGTG; SERCA3 - sense, GATGGAGTGAACGACGCA and antisense, CTCTTCTTCCGATACCTGG; SERCA2 - sense, GGAACCCAAAGG AACCAT and antisense, AACAGCCAATAGCCAAGT. 
Competitive binding assay. HeLa whole-cell lysates were, respectively, incubated with $10 \mu \mathrm{M}$ biotin, $10 \mu \mathrm{M}$ biotin-SBF-1, $10 \mu \mathrm{M}$ biotin-SBF-1 plus $100 \mu \mathrm{M}$ SBF-1 or $10 \mu \mathrm{M}$ biotin-SBF-1 plus $200 \mu \mathrm{M}$ SBF-1 and $50 \mu$ streptavidin-conjugated sepharose beads (GE Healthcare) at $4^{\circ} \mathrm{C}$ overnight for $12 \mathrm{~h}$. Then, the mixture was centrifuged at $4000 \times g$ for $1 \mathrm{~min}$ to obtain the precipitation. After washing five times with RIPA lysis buffer, the beads were boiled in $2 \times$ loading buffer $(100 \mathrm{mM}$ Tris- $\mathrm{HCl}$ (pH 6.8), 4\% SDS, $1 \%$ bromphenol blue, $20 \%$ glycerol and $2 \% \beta$-mercaptoethanol). After centrifugation at $4000 \times g$ for $2 \mathrm{~min}$, the supernatant were collected and separated with SDS-PAGE.

Silver staining and LC/MS. SDS-PAGE gels were fixed (40\% ethanol, 10\% acetic acid in distilled water) at room temperature (RT) overnight. Then, the gels were washed once with distilled water and sensitized $(150 \mathrm{ml}$ ethanol, $34 \mathrm{~g}$ anhydrous sodium acetate, $1.57 \mathrm{~g}$ anhydrous sodium thiosulfate and metered to $500 \mathrm{ml}$ with distilled water) RT for $30 \mathrm{~min}$. After washing two times, the gels were silver-stained $(0.125 \mathrm{~g}$ silver nitrate and metered to $50 \mathrm{ml})$ at RT for $20 \mathrm{~min}$. Next, the gels were washed once with distilled water and colorized with formaldehyde (20 $\mu$ l in $50 \mathrm{ml}$ distilled water) for appropriate time periods. Finally, the reaction was stopped by adding ethylene diamine tetraacetic acid $(0.1 \%$ in distilled water). Interested bands were cut and analyzed with LC/MS, which was performed by Shanghai Institute of Biochemistry Proteomics Center (Shanghai, China).

Immunofluorescence. Cells incubated with $0.1 \%$ DMSO or $10 \mu \mathrm{M}$ biotinSBF-1 for $1 \mathrm{~h}$ were fixed in $4 \%$ paraformaldehyde $(\mathrm{pH} 7.4$ ) for $30 \mathrm{~min}$. Then, the cells were softly washed two times with PBS, and incubated with $0.5 \%$ Triton X-100 for $30 \mathrm{~min}$. Thereafter, cells were softly washed two times with PBS and blocked with $3 \%$ bovine serum albumin for $1 \mathrm{~h}$. Cells were incubated with primary antibodies (anti-SERCA2 and anti-biotin antibodies, respectively) at $4^{\circ} \mathrm{C}$ overnight. After washing two times, the cells were incubated with secondary antibodies for $1 \mathrm{~h}$ and the nucleus was stained with 4, 6-diamidino-2-phenylindole (DAPI) for $1 \mathrm{~min}$. The fluorescent signals were detected with a mercury lamp (Olympus U-RFL-T) and analyzed by Image Pro Plus 6.0 software (Media Cybernetics Inc., Rockville, MD, USA).

Detection of cytosolic $\mathrm{Ca}^{2+}$ signals. Cells pretreated with DMSO or various concentrations of SBF- 1 for $48 \mathrm{~h}$ were collected and stained with Fluo-4 AM ( $2.5 \mu \mathrm{M}$ in Hank's balanced salt solution (HBSS); Gibco) for $60 \mathrm{~min}$. Then, the cells were washed two times with $\mathrm{HBSS}$ and cytosolic $\mathrm{Ca}^{2+}$ signals were detected with FACS Calibur flow cytometry (FACS; BD Biosciences, San Jose, CA, USA) or a mercury lamp (Olympus U-RFL-T).

Measurement of $\mathrm{Ca}^{2+}$-ATPase (SERCA) activity. Cells were incubated with DMSO or various concentrations of SBF-1 for $48 \mathrm{~h}$. Then, the cells were washed once with cold saline $(0.9 \%$ sodium chloride in distilled water) and resuspended with saline. After sonicated for $10 \mathrm{~s}$, SERCA activity of the suspension was measured with Super Microscale Ca ${ }^{2+}$-ATPase Detection Kit (A070-4; Nanjing Jiancheng Bioengineering Institute, Nanjing, China) according to the manufacturer's protocols.

Plasmids and lentivirus. Construction of pcDNA3.1(+)-hSERCA2b was performed as before. ${ }^{19}$ Construction of sh-SERCA2 lentivirus was performed by Neuron Biotechnology (Shanghai, China). The vector of the shRNA was pLKDCMV-G\&PR-U6 and the map was shown in Supplementary Figure S1; the sequence was $5^{\prime}$-CAAAGUUCCUGCUGAUAUA- $3^{\prime}$. Control lentivirus particles were provided by Neuron Biotechnology and the sequence was $5^{\prime}$-UUCUC CGAACGUGUCACGU- $3^{\prime}$. For transient transfection, cells were seeded into six-well plates and allowed to grow to $40 \%$ confluence. Then, $2 \mu \mathrm{g}$ pcDNA3.1(+) or pcDNA3.1(+)-hSERCA2b together with $2 \mu$ l Lipofectamine 2000 (Life Technologies) were added into the cells, respectively. Twenty-four hours after transfection, the cells were incubated with DMSO or various concentrations of SBF- 1 for another $48 \mathrm{~h}$. For lentivirus infection, $1 \times 10^{5}$ cells in a well were seed into 12-well plates. Twelve hours later, $1 \times 10^{6}$ plaque-forming units of control lentivirus particles or sh-SERCA2 lentivirus particles were added to the cells, respectively. Three days after infection, the infected cells were incubated with $8 \mu \mathrm{g} / \mathrm{ml}$ puromycin (P8833; Sigma) for another 2 weeks. Then, the cells were harvested and the protein levels of SERCA2 were detected with immunoblotting. Cells stably infected with control or sh-SERCA2 lentivirus were incubated with DMSO at various concentrations of SBF-1 for $48 \mathrm{~h}$. Then, the cells were collected for the following experiments.
In vivo tumor xenografts model. One million HeLa cells (in $0.1 \mathrm{ml} \mathrm{PBS}$ ) were subcutaneously injected into the right flanks of nude mice. Seven days later, all the mice formed visible tumors. Then, the mice were distributed into two groups according to tumor volumes. Vehicle $(0.1 \%$ DMSO in PBS, $n=5)$ and $5 \mu \mathrm{g} / \mathrm{kg}$ SBF-1 $(n=6)$ were daily intraperitoneally injected to the tumor-bearing mice for 12 days. Body weight and tumor volumes were measured and recorded every 2 days. Long diameter $(L)$ and short diameter $(S)$ of a tumor were measured with a vernier caliper and the tumor volume was calculated as follows: $L \times S^{2} / 2$. Twelve days after injection, the mice were killed and tumors were separated. Tumor weight was measured and tumor sections were fixed in formalin. The rest of the sections were frozen in liquid nitrogen and stored at $-80^{\circ} \mathrm{C}$.

Immunohistochemistry and TUNEL staining. Paraffin sections of xenografts were cut into 5 - $\mu$ m-thick sections. Then, the sections were infused in xylene (10 min per time for three times), followed by infusion in $90 \%$ ethanol ( $3 \mathrm{~min}$ ), $75 \%$ ethanol $(3 \mathrm{~min}), 50 \%$ ethanol $(3 \mathrm{~min})$ and $\mathrm{ddH}_{2} \mathrm{O}(3 \mathrm{~min})$. For immunohistochemistry, the sections were boiled in antigen restoration solution (P0081; Beyotime) for $3 \mathrm{~min}$ and cooled naturally. Cooled sections were incubated with $3 \%$ $\mathrm{H}_{2} \mathrm{O}_{2}$ at RT for 10 min and blotted with $3 \%$ horse serum for $1 \mathrm{~h}$. Next, the sections were incubated with primary antibodies at $4{ }^{\circ} \mathrm{C}$ overnight. The following steps were in accordance to the protocols provided by the manufacturer of GTVision III Detection System/Mo\&Rb (GK500705; Gene Tech Company Limited, Shanghai, China). The nucleus was stained with hematoxylin. TUNEL staining was performed according to the instructions provided by the manufacturer of DeadEnd Fluorometric TUNEL System (TB235; Promega, Madison, WI, USA). The nucleus was stained with DAPI (Beyotime) for $1 \mathrm{~min}$ and the percentage of TUNEL-positive cells was calculated with a mercury lamp (Olympus U-RFL-T).

Statistical analysis. Data are expressed as means \pm S.D. One-way ANOVA was used to evaluate the differences among more than three groups. The Student's $t$-test was used to evaluate the difference between two groups. $P<0.05$ was considered to be significant.

\section{Conflict of Interest}

The authors declare no conflict of interest.

Acknowledgements. This work was supported by the National Natural Science Foundation of China (Nos. 81330079, 91229109, 81273528, 81422050), Jiangsu Province Clinical Science and Technology Project (Clinical Research Center, BL2012008) and National Science and Technology Major Project (No. 2012ZX09304-001).

1. Malhotra JD, Kaufman RJ. ER stress and its functional link to mitochondria: role in cell survival and death. Cold Spring Harbor Perspect Biol 2011; 3: a004424.

2. Wang WA, Groenendyk J, Michalak M. Endoplasmic reticulum stress associated responses in cancer. Biochim Biophys Acta 2014; 1843: 2143-2149.

3. Vandewynckel YP, Laukens D, Geerts A, Bogaerts E, Paridaens A, Verhelst X et al. The paradox of the unfolded protein response in cancer. Anticancer Res 2013; 33: 4683-4694.

4. Kozutsumi Y, Segal M, Normington K, Gething MJ, Sambrook J. The presence of malfolded proteins in the endoplasmic reticulum signals the induction of glucose-regulated proteins. Nature 1988; 332: 462-464.

5. Hetz C, Martinon F, Rodriguez D, Glimcher LH. The unfolded protein response: integrating stress signals through the stress sensor IRE1alpha. Physiol Rev 2011; 91: 1219-1243.

6. Walter $P$, Ron D. The unfolded protein response: from stress pathway to homeostatic regulation. Science 2011; 334: 1081-1086.

7. Chakrabarti A, Chen AW, Varner JD. A review of the mammalian unfolded protein response. Biotechnol Bioeng 2011; 108: 2777-2793.

8. Logue SE, Cleary P, Saveljeva S, Samali A. New directions in ER stress-induced cell death. Apoptosis 2013; 18: 537-546.

9. Brini M, Carafoli E. Calcium pumps in health and disease. Physiol Rev 2009; 89: 1341-1378.

10. Arbabian A, Brouland JP, Gelebart P, Kovacs T, Bobe R, Enouf J et al. Endoplasmic reticulum calcium pumps and cancer. Biofactors 2011; 37: 139-149.

11. Periasamy $M$, Kalyanasundaram A. SERCA pump isoforms: their role in calcium transport and disease. Muscle Nerve 2007; 35: 430-442.

12. Monteith GR, McAndrew D, Faddy HM, Roberts-Thomson SJ. Calcium and cancer: targeting $\mathrm{Ca}^{2+}$ transport. Nat Rev Cancer 2007; 7: 519-530.

13. Papp B, Brouland JP. Altered endoplasmic reticulum calcium pump expression during breast tumorigenesis. Breast Cancer (Auckl) 2011; 5: 163-174. 
14. Gou WF, Niu ZF, Zhao S, Takano Y, Zheng HC. Aberrant SERCA3 expression during the colorectal adenoma-adenocarcinoma sequence. Oncol Rep 2014; 31: 232-240.

15. Arbabian A, Brouland JP, Apati A, Paszty K, Hegedus L, Enyedi A et al. Modulation of endoplasmic reticulum calcium pump expression during lung cancer cell differentiation. FEBS J 2013; 280: 5408-5418.

16. Korosec B, Glavac D, Volavsek M, Ravnik-Glavac M. ATP2A3 gene is involved in cancer susceptibility. Cancer Genet Cytogenet 2009; 188: 88-94.

17. Brouland JP, Gelebart P, Kovacs T, Enouf J, Grossmann J, Papp B. The loss of sarco/ endoplasmic reticulum calcium transport ATPase 3 expression is an early event during the multistep process of colon carcinogenesis. Am J Pathol 2005; 167: 233-242.

18. Gelebart P, Kovacs T, Brouland JP, van Gorp R, Grossmann J, Rivard N et al. Expression of endomembrane calcium pumps in colon and gastric cancer cells. Induction of SERCA3 expression during differentiation. J Biol Chem 2002; 277: 26310-26320.

19. Wang L, Song R, Shen Y, Sun Y, Gu Y, Shu Y et al. Targeting sarcoplasmic/endoplasmic reticulum $\mathrm{Ca}(2)+-$-ATPase 2 by curcumin induces ER stress-associated apoptosis for treating human liposarcoma. Mol Cancer Ther 2011; 10: 461-471.

20. Prasad V, Boivin GP, Miller ML, Liu LH, Erwin CR, Warner BW et al. Haploinsufficiency of Atp2a2, encoding the sarco(endo)plasmic reticulum $\mathrm{Ca}^{2+}$-ATPase isoform $2 \mathrm{Ca}^{2+}$ pump, predisposes mice to squamous cell tumors via a novel mode of cancer susceptibility. Cancer Res 2005; 65: 8655-8661.

21. Korosec B, Glavac D, Rott T, Ravnik-Glavac M. Alterations in the ATP2A2 gene in correlation with colon and lung cancer. Cancer Genet Cytogenet 2006; 171: 105-111.

22. Siegel R, Ma J, Zou Z, Jemal A. Cancer statistics, 2014. CA Cancer J Clin 2014; 64: 9-29.

23. Siegel R, Naishadham D, Jemal A. Cancer statistics, 2013. CA Cancer J Clin 2013; 63: $11-30$.

24. Yee GP, de Souza P, Khachigian LM. Current and potential treatments for cervical cancer. Curr Cancer Drug Targets 2013; 13: 205-220.

25. Hanahan D, Weinberg RA. Hallmarks of cancer: the next generation. Cell 2011; 144: 646-674.

26. Hanahan D, Weinberg RA. The hallmarks of cancer. Cell 2000; 100: 57-70.

27. Wong VK, Li T, Law BY, Ma ED, Yip NC, Michelangeli F et al. Saikosaponin-d, a novel SERCA inhibitor, induces autophagic cell death in apoptosis-defective cells. Cell Death Dis 2013; 4: e720.

28. Roti G, Carlton A, Ross KN, Markstein M, Pajcini K, Su AH et al. Complementary genomic screens identify SERCA as a therapeutic target in NOTCH1 mutated cancer. Cancer Cell 2013; 23: 390-405.

29. Li W, Song R, Fang X, Wang L, Chen W, Tang P et al. SBF-1, a synthetic steroidal glycoside, inhibits melanoma growth and metastasis through blocking interaction between PDK1 and AKT3. Biochem Pharmacol 2012; 84: 172-181.
30. Shi B, Wu H, Yu B, Wu J. 23-Oxa-analogues of OSW-1: efficient synthesis and extremely potent antitumor activity. Angew Chem 2004; 43: 4324-4327.

31. Ozcan U, Yilmaz E, Ozcan L, Furuhashi M, Vaillancourt E, Smith RO et al. Chemical chaperones reduce ER stress and restore glucose homeostasis in a mouse model of type 2 diabetes. Science 2006; 313: 1137-1140.

32. Taruno A, Niisato N, Marunaka Y. Intracellular calcium plays a role as the second messenger of hypotonic stress in gene regulation of SGK1 and ENaC in renal epithelial A6 cells. Am J Physiol Renal Physiol 2008; 294: F177-F186.

33. Sovolyova N, Healy S, Samali A, Logue SE. Stressed to death - mechanisms of ER stressinduced cell death. Biol Chem 2014; 395: 1-13.

34. Fu S, Yang L, Li P, Hofmann O, Dicker L, Hide W et al. Aberrant lipid metabolism disrupts calcium homeostasis causing liver endoplasmic reticulum stress in obesity. Nature 2011; 473: 528-531.

35. Zismanov V, Drucker L, Gottfried M. ER homeostasis and motility of NSCLC cell lines can be therapeutically targeted with combined Hsp90 and HDAC inhibitors. Pulm Pharmacol Ther 2013; 26: 388-394.

36. Dubois C, Vanden Abeele F, Sehgal P, Olesen C, Junker S, Christensen SB et al. Differential effects of thapsigargin analogues on apoptosis of prostate cancer cells: complex regulation by intracellular calcium. FEBS J 2013; 280: 5430-5440.

37. Janssen K, Horn S, Niemann MT, Daniel PT, Schulze-Osthoff K, Fischer U. Inhibition of the $\mathrm{ER} \mathrm{Ca}^{2+}$ pump forces multidrug-resistant cells deficient in Bak and Bax into necrosis. J Cell Sci 2009; 122: 4481-4491.

38. Dong Y, Zhang M, Liang B, Xie Z, Zhao Z, Asfa S et al. Reduction of AMP-activated protein kinase alpha2 increases endoplasmic reticulum stress and atherosclerosis in vivo. Circulation 2010; 121: 792-803.

39. Liang CP, Han S, Li G, Tabas I, Tall AR. Impaired MEK sign aling and SERCA expression promote ER stress and apoptosis in insulin-resistant macrophages and are reversed by exenatide treatment. Diabetes 2012; 61: 2609-2620.

(c) (i) Cell Death and Disease is an open-access journal published by Nature Publishing Group. This work is

licensed under a Creative Commons Attribution 4.0 International Licence. The images or other third party material in this article are included in the article's Creative Commons licence, unless indicated otherwise in the credit line; if the material is not included under the Creative Commons licence, users will need to obtain permission from the licence holder to reproduce the material. To view a copy of this licence, visit http://creativecommons.org/licenses/by/4.0

\section{Supplementary Information accompanies this paper on Cell Death and Disease website (http://www.nature.com/cddis)}

